\title{
5 Gradable predicates and intensifiers
}

The aim of the current chapter is twofold: on the one hand it contains a discussion of the semantics of gradable predicates and on the other hand, it presents an analysis of degree expressions. In the process, it provides the background for the following chapters. The starting point for the discussion of gradable predicates is gradable adjectives. In section 5.1, I will start with a discussion of the semantics of gradable adjectives, focusing on the analyses of Kennedy (1999b, 2007) and Kennedy \& McNally (2005a) on the one hand, and Löbner (1990) on the other.

In 5.2, I will turn to the analysis of degree expressions, starting with a discussion of their semantic type and a subclassification of different types of degree expressions. The focus of 5.3 is the semantics of intensifiers like English very and German sehr. Finally, I turn in 5.4 to verbs and discuss how verbs fit into the analysis of gradable predicates. On the one hand, similarities and differences with regard to gradable adjectives are discussed, on the other hand specific questions with respect to the encoding of scales in verbs are formulated.

\subsection{Gradable adjectives}

Different analyses of gradable adjectives have been proposed in the literature (e.g. Cresswell 1976; Klein 1980, 1982; Bierwisch 1989; Löbner 1990; Kennedy 1999b,a; Kennedy \& McNally 2005a). ${ }^{1}$ In 5.1.1, I will start with a discussion of Kennedy's and Kennedy \& McNally's approach of the semantics of gradable adjectives. Then I will turn in 5.1.2 to Löbner's (1990) approach, which makes use of a different theoretical framework.

See Kennedy (1999b) as well as Morzycki (2013, chap. 3) for a summary of previous accounts on the semantics of gradable adjectives and see Carstensen (2013) for a comparison of Bierwisch's and Kennedy's approach. 


\subsubsection{Kennedy \& McNally (2005a)}

In their subsequent work, Kennedy (1999b,a, 2007) and Kennedy \& McNally $(2005 a, b)$ present a degree-based analysis of gradable adjectives. ${ }^{2}$ Degrees figure prominently in this analysis as an ontological type 'd' for degrees is assumed. Degrees, as abstract representations of measurement, are conceived of the logical type 'd.' The nature and status of degrees has been discussed by authors like Cresswell (1976) and von Stechow (2008), who analyze degrees as equivalence classes of objects which are indistinguishable with regard to a certain property. ${ }^{3}$ The definition of equivalence classes is based on the transitive and antisymmetric 'more than' relation ('>'). '> beau', for example, stands for the empirical relation 'more beautiful/prettier than.' Basically, an equivalence relation ('= two individuals $\mathrm{x}$ and $\mathrm{y}$ are of equal beauty. This holds in the case that for any $y$, if $x$ is more beautiful than $z, y$ is also more beautiful than $z$. And also the reverse holds: if $\mathrm{z}$ is more beautiful than $\mathrm{x}, \mathrm{z}$ is also more beautiful than $\mathrm{y}$. This means that $\mathrm{x}$ and $\mathrm{y}$ are indistinguishable with respect to beauty. A formal definition is presented in (1); $\mathrm{F}\left(>={ }_{\text {beau }}\right)$ is the field of the relation 'more beautiful/prettier than.'

$$
\begin{aligned}
& \mathrm{x}=\text { beau } \mathrm{y} \text { " } \mathrm{x} \text { is exactly as beautiful as } \mathrm{y} \text { " } \\
& \left(\forall \mathrm{x}, \mathrm{y} \in \mathrm{F}\left(>_{\text {beau }}\right)\right)[\mathrm{x}=\text { beau } \mathrm{y}] \text { iff }\left(\forall \mathrm{z} \in \mathrm{F}\left(>_{\text {beau }}\right)\right)\left[\mathrm{x}>_{\text {beau }} \mathrm{z} \text { iff } \mathrm{y}\right. \\
& \left.>_{\text {beau }} \mathrm{z}\right] \&\left[z>_{\text {beau }} \mathrm{x} \text { iff } \mathrm{z}>_{\text {beau }} \mathrm{y}\right] \\
& \text { (von Stechow, 2008, 3) }
\end{aligned}
$$

Degrees of beauty can be defined as all the equivalence classes generated by $=_{\text {beau }}$, as shown in (2). Applied to a concrete example such as Angela is beautiful we get the equivalence class [Angela $]_{\text {beau }}$ as the degree of her beauty, which, following von Stechow $(2008,3)$, is tantamount to 'Angela is beautiful to the degree she is.' One the one hand, this is a trivial statement,

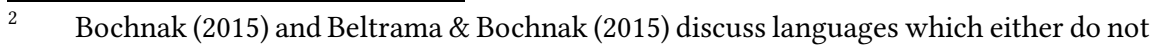
have degree constructions, such as Washo, or make use of modifiers which apparently look like intensifiers but are also used in non-degree contexts. The authors propose an analysis, for these constructions/languages, which does not rely on degrees. Such languages are not in the scope of this thesis.

3 See Morzycki $(2013,115)$ for some problems with this account of 'degrees' and also for other analyses of this notion. See, for example, Anderson \& Morzycki (2015) for an explication of degrees as kinds (of states). 
one the other hand it is exactly this triviality which shows, as von Stechow $(2008,3)$ says, that introducing degrees is innocuous.

$$
\begin{aligned}
& \text { Degrees of beauty: } \\
& \left(\forall \mathrm{x} \in \mathrm{F}\left(>_{\text {beau }}\right)\right)[\mathrm{x}]_{\text {beau }}=\left\{\mathrm{y} \mid \mathrm{y}=\text { beau }_{\text {be }}\right\} \\
& \operatorname{Deg}_{\text {beau }}=\left\{[\mathrm{x}]_{\text {beau }} \mid \mathrm{x} \in \mathrm{F}\left(>_{\text {beau }}\right)\right\} \\
& (\text { von Stechow, 2008, 3) }
\end{aligned}
$$

By taking degrees to be equivalence classes, hence as sets of objects, they do not necessarily represent a new ontological type. Since they denote sets of objects, we can assign them the type of set denoting expressions $\langle e, t\rangle$. Therefore, type ' $\mathrm{d}$ ' could be conceived as an abbreviation for equivalence classes. Kennedy $(2001,34 \mathrm{n} 1)$ follows the analysis of degrees as equivalence classes but also seems to assume that ' $\mathrm{d}$ ' is an irreducible ontological type. I follow von Stechow's explication of the notion of 'degrees' but remain uncommitted as to whether degrees should be conceived of as an irreducible ontological type or not.

In Kennedy's and Kennedy \& McNally's approach, gradable adjectives are analyzed as measure functions. Measure functions map individuals onto scales and return the degree of the individuals on the scale. Such measure functions are of type $\langle e, d\rangle$. The adjective warm can be analyzed as the measure function $\operatorname{WARM}(\mathrm{x})$, which is a function from the domain of individuals that have temperature to degrees of temperature. Measure functions do not express properties of individuals but need to be converted into such expressions by degree morphology. "Degree morphemes serve two functions: they introduce an individual argument for the measure function denoted by the adjective and they impose some requirement on the degree derived by applying the adjective to its argument, typically by relating it to another degree" (Kennedy, 2007, 5). One of the degree morphemes assumed by Kennedy and Kennedy \& McNally is the positive morpheme pos which turns a measure function into the positive form of an adjective. There is a type-theoretic and thereby theory-internal reason to postulate the morphological null pos morpheme, as it is required to convert measure functions into properties of individuals. By applying pos to a measure function of type $\langle e, d\rangle$ we get an expression of the type $\langle\langle e, d\rangle, t\rangle$. Before we turn to the semantics of pos, I would like to discuss the linguistic evidence for the assumption of pos. 
Several authors, for example Cresswell (1976); von Stechow (1984); Kennedy (1999b,a) as well as Kennedy \& McNally (2005a,b), assume a morphological null pos morpheme. Sinitic languages provide evidence for such a morpheme as they require an explicit marking of the positive form of adjectives. In these languages a degree expression is required for a positive reading of adjectives as bare uses of (some) adjectives results in a comparative reading. This is illustrated for Mandarin Chinese, Cantonese and Fuyang Wu in (3) to (5). The Mandarin Chinese example in (3a) only yields a comparative reading; if no comparandum is realized, it is contextually supplied. The addition of the degree expression hěn 'very' yields a positive reading (cf. the discussion in chapter 2). Matthews \& Yip (1994) mention that in Cantonese a predicatively used adjective also requires the addition of a degree expression to yield a positive interpretation (4). The same is shown by the data from Fuyang $\mathrm{Wu}$ (5), in which case the degree expression man 'very' is required for a positive reading. Unlike Mandarin Chinese, Fuyang Wu requires the addition of a different degree expression for a comparative reading if no comparandum is realized (5b).

(3) Mandarin Chinese (Sinitic < Sino-Tibetian; Sybesma 1999, 27)

a. Zhāngsān gāo.

Zhangsan tall

'Zhangsan is taller (than someone else known from context).'

b. Zhāngsān hĕn gāo.

Zhangsan very tall

'Zhangsan is tall.'

(4) Cantonese (Sinitic < Sino-Tibetian; Matthews \& Yip 1994, 158)

Léih go jái hóu gōu.

you CLA son very tall

'Your son is tall.'

(5) Fuyang $\mathrm{Wu}$ (Sinitic $<$ Sino-Tibetian; Xuping Li, p.c.)
a. $k \gamma$ ciopix $x k \varepsilon n$ cin
CLA girl good-looking a bit
'The girl is better looking.'
b. $k \mathrm{y}$ ciopi man $x \mathrm{okn}$
CLA girl very good-looking
'The girl is good-looking.' 
The assumption of a positive morpheme is not crucial for Kennedy's proposal and he mainly proposes that the positive morpheme keep the compositional analysis of the positive form parallel to other forms that make use of overt degree morphology (like the comparative or superlative constructions). Kennedy $(2007,7)$ states that one can either assume a zero positive morpheme or one can take the absence of overt positive morphology seriously and simply assume a type-shifting rule that turns a measure function into a property of individuals (see Neeleman et al. 2004 for such a solution). I will discuss the question whether we need to assume a verbal pos morpheme in section 5.4 and turn now to the semantics of pos.

The semantics of pos looks like in (6). $g$ is a variable for gradable adjectives and $s$ is "a context-sensitive function from measure functions to degrees that returns a standard of comparison based both on properties of the adjective $g$ (such as its domain) and on features of the context of utterance" (Kennedy, 2007, 16). ${ }^{4}$ Kennedy further states that $s$ chooses a standard of comparison which ensures that the positive form is true in the context of utterance. ${ }^{5}$ The standard is the cutoff point which determines of which degrees the positive form is true and of which it is not. This cutoff point is determined by the degree returned by $s$, and therefore $s$ specifies the minimal degree for an individual such that the predication is true.

$$
\begin{aligned}
& \llbracket p o s \rrbracket=\lambda \mathrm{g} \lambda \mathrm{x} .(\mathrm{g}(\mathrm{x}) \geq \mathbf{s}(\mathrm{g})) \\
& \text { (Kennedy, 2007, 17) }
\end{aligned}
$$

Applying pos to the gradable adjective tall yields the denotation in (7). An individual $x$ is tall if its degree on the scale associated with tall exceeds the contextual standard for tall.

$$
\llbracket[\operatorname{pos}[\operatorname{tall}]] \rrbracket=\lambda \mathrm{x} \cdot \operatorname{tall}(\mathrm{x}) \geq \mathbf{s}(\text { tall })
$$

For gradable absolute adjectives such as full, for example, the standard is not context-dependent. Instead, these adjectives lexically indicate an

\footnotetext{
$4 \quad$ One has to keep in mind that different types of standards or norms, as Leisi (1971) calls it, need to be distinguished. As I argued in chapter 2.2, all the types of norms identified by Leisi are context-dependent and can probably be captured by Kennedy's analysis.

5 See Kennedy $(2007,16 \mathrm{ff}$.) for a discussion of domain restrictions with respect to standards of comparison.
} 
appropriate comparison degree. For absolute adjectives that are closed at the lower end like straight, $d$ is ' $>\min \left(\mathrm{S}_{A}\right)$ ', which means that the degree has to exceed the minimal degree on the adjective's scale. For absolute adjectives that are closed at the upper end, $d$ is equated with the maximal degree on the associated scale. The truth conditions for adjectival phrases headed by absolute adjectives are shown in (8). The representations are based on Kennedy \& McNally $(2005 \mathrm{a}, 358)$ but adapted to the representational format of Kennedy (2007). $S_{g}$ stands for the scale associated with the adjective and $\mathbf{m i n}$ and $\mathbf{m a x}$ for functions that return the minimal and maximal degree of the scale.

$$
\begin{array}{ll}
\text { a. } & \llbracket \mathrm{AP}_{\min } \rrbracket=\lambda \mathrm{x} \cdot \mathrm{g}(\mathrm{x})>\min \left(\mathrm{S}_{g}\right) \\
\text { b. } & \llbracket \mathrm{AP}_{\max } \rrbracket=\lambda \mathrm{x} \cdot \mathrm{g}(\mathrm{x})=\max \left(\mathrm{S}_{g}\right)
\end{array}
$$

Kennedy (2007) assumes that gradable adjectives directly denote measure functions. The degree argument, meaning the standard of comparison, and the relational component (whether the degree of $x$ has to exceed the standard or not) are introduced by degree morphology. Kennedy \& McNally (2005a) take a different stance and follow Cresswell (1976); von Stechow (1984) and Bierwisch (1989) among others in assuming that gradable adjectives express relations between individuals and degrees. They propose the denotation in (9) for an adjective like expensive. The degree returned by the measure functionEXPENSIVE is compared to a comparison degree $d$. In this case, the function of degree expressions is to saturate the degree argument and thereby to specify the standard of comparison.

$$
\llbracket \text { expensive } \rrbracket=\lambda \mathrm{d} \lambda \text { x.expensive }(\mathrm{x})=\mathrm{d}
$$

(Kennedy \& McNally, 2005a, 349)

A simplified version of their (Kennedy \& McNally, 2005a, 350) representation of pos is shown in (10). pos binds the degree argument and thereby specifies the comparison degree. The standard relation holds "of a degree $d$ just in case it meets a standard of comparison for an adjective $G$ with respect to a comparison class determined by $C$, a variable over properties of individuals whose value is determined contextually" (Kennedy \& McNally, 2005a, 35). As Bochnak (2013a, 51) writes: "the norm-related interpretation of the bare form [i.e., positive form] is not lexicalized in the gradable adjectives themselves, but rather is contributed by pos."

$$
\llbracket \text { pos } \rrbracket=\lambda \mathrm{G} \lambda \mathrm{x} . \exists \mathrm{d}\left[\mathrm{d}>\operatorname{standard}_{C}(\mathbf{G}) \wedge \mathbf{G}(\mathbf{d})(\mathbf{x})\right]
$$


Kennedy \& McNally (2005a) propose a general template for degree expressions and assume that all degree expressions convert measure functions into properties of individuals by introducing a standard of comparison. Degree expressions, as they state, impose restrictions on the comparison degree. The general degree expressions template can be formulated (based on the proposal in Kennedy \& McNally 2005a, 367) like in (11). The idea is that a degree expression takes a gradable adjective $G$ as its argument and provides a restriction $R$ on the comparison degree.

$$
\begin{aligned}
& \llbracket \mathrm{DEG}(\mathrm{P}) \rrbracket=\lambda \mathrm{G} \lambda \mathrm{x} \cdot \exists \mathrm{d}[\mathrm{R}(\mathrm{d}) \wedge \mathrm{G}(\mathrm{d})(\mathrm{x})] \\
& \text { (Kennedy \& McNally, 2005a, 367) }
\end{aligned}
$$

Pos is an instantiation of the general template in (11) and imposes a restriction on $d$ in terms of the standard relation. The semantic representations of two other degree expressions are shown in (12). (12a) shows the representation of the measure phrase two meters and (b) shows it for the degree expression completely. The measure phrase two meters restricts the degree to a value which is equal or higher than two meters, whereas completely equates it with the maximal degree on the scale.

$$
\begin{array}{ll}
\text { a. } & \llbracket \text { two meters } \rrbracket=\lambda \mathrm{G} \lambda \mathrm{x} . \exists \mathrm{d}[\mathrm{d} \geq \text { two meters } \wedge \mathrm{G}(\mathrm{d})(\mathrm{x})] \\
\text { b. } & \llbracket \text { completely } \rrbracket=\lambda \mathrm{G} \lambda \mathrm{x} . \exists \mathrm{d}\left[\mathrm{d}=\mathbf{m a x}\left(\mathrm{S}_{G}\right) \wedge \mathrm{G}(\mathrm{d})(\mathrm{x})\right] \\
& \text { (Kennedy \& McNally, 2005a, 368f.) }
\end{array}
$$

In accordance with the view that pos is an instatiation of the general degree template in (11) and therefore behaves like other degree expressions, one can say that the morphologicaly null pos morpheme completes "a paradigm whose other members do have overt counterparts” (Bochnak, 2013a, 59) and therefore can be seen as "an appropriate technical solution for a unified analysis of the paradigm" (Bochnak, 2013a, 60). But I will show later that not all degree expressions are of the same type and therefore the general template is not adequate for capturing the compositional semantics of the various degree expressions.

\subsubsection{Löbner (1990)}

In his 1990 monograph, Löbner describes the conceptual format of 'phase quantification.' In his view, phase quantification is a general mechanism 
which can be applied to a semantic analysis of genuine quantifiers, gradable adjectives, aspectual particles like German schon 'already' and noch 'still' ${ }^{6}$ but also grammatical operators such as aspect or modality (cf. the overview in Löbner 1990, 2011b). As Löbner (2011b) states, the notion of 'phase quantification' is somewhat misleading and in fact it is essentially a unifying scalar approach to the aforementioned phenomena.

Löbner (2011b, 504) describes phase quantification as follows: "Phase quantification is about some first-order predication $\mathrm{p}$; the truth value of $\mathrm{p}$ depends on the location of its argument on some scale; for example $\mathrm{p}$ may be true of $t$ only if $t$ is located beyond some critical point on the scale." Basically, phase quantification is about the location of an argument on a scale and concerns the question how the argument is located with regard to the critical point on that scale. This critical point separates a scale into a phase for which the predication is true and one for which it is false. Four types of phase quantifiers can be distinguished with regard to the order of the phases and the location of the argument.

Figure 10 is a graphical illustration of the four types of phase quantifiers. $P$ marks the respective phase on the scale for which the predication holds true. $t$ is the argument assigned to one of the phases. In (a) the predication is true for higher cases on the scale, but false for lower ones. The argument $t$ is assigned to the phase for which $P$ is true. (b) presents the reversed order of phases; the predication is true for lower cases on the scale, and $t$ is assigned to the phase for which the predication is true. Both types in (c) and (d) equal (a) and (b) respectively in the order of the two phases, but $t$ is assigned to different phase respectively. Natural language examples taken from the domain of gradable adjectives that illustrate the four types in figure 10 are tall for (a), its antonym short for (b), not tall for (c) and finally not short for (d). For tall the predication is true for degrees higher on the scale than the critical point. Phase quantification leads to a contrast between those higher degrees, which are marked for size, and lower degrees that count as 'not-tall.' Small on the other hand provides a contrast between those degrees that count as 'small' in a certain context of use and higher degrees on the scale which do not count as 'small' anymore. The four types

These particles are also often called 'Gradpartikel' (degree particles) in German, which seems to be rather misleading terminology since they are not used as gradation devices. 
of phase quantification, illustrated in figure 10, are not all lexicalized. With respect to adjectives only the types illustrated in (a) and (b) are lexicalized (tall vs. short), whereas those in (c) and (d) are expressed by negation (cf. Löbner 1985, 1990 for a discussion of the differences in lexicalization of the four types of phase quantifiers).

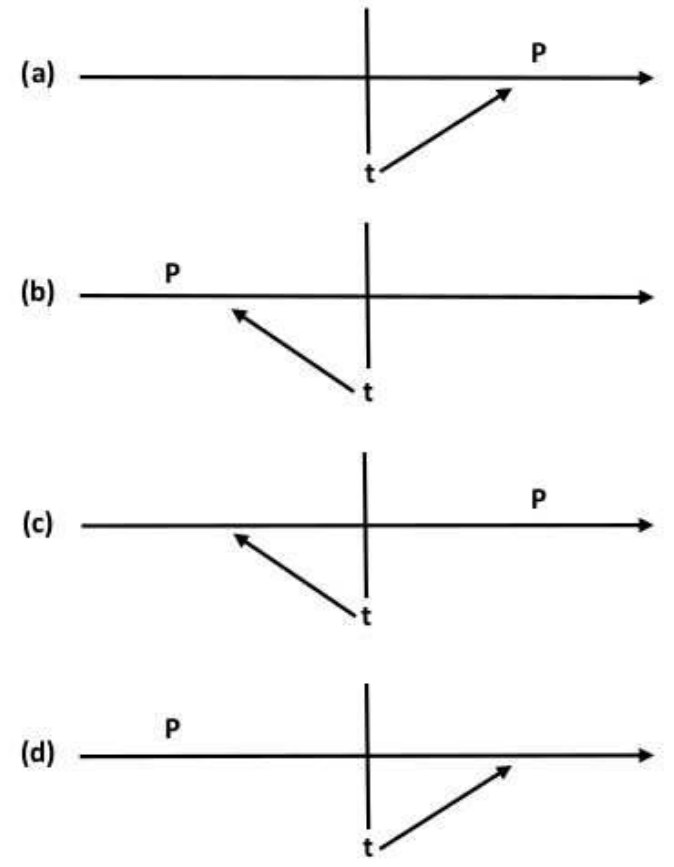

Figure 10: Graphical representations of the four different types of phase quantifiers.

Löbner (1990, 2011b) bases his explication of phase quantification on a definition of 'admissible $\alpha$-intervals' (13). An admissible $\alpha$-interval is a section of a scale which is divided into at most one positive and one negative phase. A positive phase is one for which the predication is true, a negative one for which it is false. $\alpha$ represents the truth value of $p$ for the first section on the phase. 
(13) Let $\mathrm{p}$ be a predicate expression with domain $\mathrm{D},<$ a partial ordering in $\mathrm{D}, \mathrm{t} \in \mathrm{D}$ and $\alpha=0$ or 1 . The set of admissible $\alpha$-intervals in terms of $<, \mathrm{p}$ and $\mathrm{t}-\operatorname{AI}(\alpha,<, \mathrm{p}, \mathrm{t})-$ is the set of all subsets of $\mathrm{D}$ which

(i) are linearly ordered by $<$

(ii) contain $\mathrm{t}$ and some $\mathrm{t}^{\prime}<\mathrm{t}$

(iii) start with a phase of $[\mathrm{p}]=\alpha$

(iv) contain at most one transition from not-p to $p$ below $t$.

(Löbner, 2011b, 503)

The partial ordering in $D$ is, in the case of gradable adjectives, lexically specified by the predicate. Each gradable adjective specifies a scale on which the elements in $D$ can be ordered. Based on this definition, a general definition of phase quantification is given in (14).

(14) Phase quantification:

Given the conditions of definition (13), $\mathrm{PQ}(\alpha,<, \mathrm{p}, \mathrm{t}) \equiv_{d f} \exists \forall \mathrm{I}(\mathrm{I} \in$ $\mathrm{AI}(\alpha,<, \mathrm{p}, \mathrm{t}): \mathrm{p}(\mathrm{t}))$.

(Löbner, 2011b, 503)

The definition in (14) makes use of the homogenous quantifier $\exists \forall$, which is defined in (15). It is a quantifier that takes two arguments and essentially expresses that "the b's are p" as Löbner (2011b, 491)) states.

$$
\begin{aligned}
& \exists \forall \mathrm{x}(\mathrm{b}: \mathrm{p})=d_{f f} \exists \mathrm{x}(\mathrm{b} \wedge \mathrm{p}) \text { iff }[\exists \mathrm{x}(\mathrm{b} \wedge \mathrm{p})=\forall \mathrm{x}(\mathrm{b} \rightarrow \mathrm{p})] \text {, otherwise } \\
& \text { undefined. }
\end{aligned}
$$

(Löbner, 2011b, 491, Löbner, 1990, 28)

For the definition of phase quantification this warrants that each phase leads to a homogeneous predication regarding the crucial property $p$. Gradable adjectives like small and tall provide an ordering of their (shared) domain with respect to the size of the elements in the domain. In the case of tall, $\alpha$ is 0 . Hence, it starts with a phase for which the predication $p$ does not hold and then there is a transition to a phase for which it holds. The argument of the predication is assigned to the second phase. For small it is reversed, its partitioning of the scale starts with a phase for which the predication holds and then there is a transition to a phase for which the predication is false. This leads to a contrast between lower degrees, for which small is true, and higher degrees for which it is not. The argument 
of the predication is assigned to the first phase. (16) shows the semantic representation for gradable adjectives as phase quantifiers. $t$ is bound by a lambda operator and represents the syntactic argument of the adjective. The respective predication is expressed by $\lambda \mathrm{t}^{\prime}\left(\mathrm{gt} \mathrm{t}^{\prime}=\mathrm{x}\right)$, which specifies that the degree of $t^{\prime}$ is either 1 or 0 , meaning that it is either marked with regard to the expressed property or not.

$$
\begin{aligned}
& \lambda \mathrm{t} \text { PQ1 }\left(<, \mathrm{t}, \lambda \mathrm{t}^{\prime}\left(\mathrm{gt}^{\prime}=\mathrm{x}\right)\right) \\
& \text { (based on Löbner, 1990, 161) }
\end{aligned}
$$

Degree expressions can be conceived as phase quantifiers similarly to gradable adjectives. Löbner $(1990,162,166)$ presents a formal analysis of, for example, the comparative construction but also of degree expressions like German viel 'much, many' and wenig 'little'. These degree expressions are analyzed as gradable adjectives, and with respect to viel Löbner assumes that it makes a predication about the quantity of its argument. But neither Löbner nor Ropertz (2001) provide an analysis of sehr in terms of phase quantification but suggest that such an analysis should be straightforwardly possible (see Fleischhauer (2013) for a first attempt of analyzing sehr as a phase quantifier). The main advantage of the phase quantificational approach is that it provides a general format for the semantic analysis of apparently unrelated linguistic expressions such as genuine quantifiers, gradable adjectives and aspect. So far the structural properties of scales - the presence vs. absence of minimal/maximal scale values - have not been integrated into the phase quantificational approach. ${ }^{7}$

As Löbner's approach is less widely used than the one from Kennedy and Kennedy \& McNally, I opt for the latter account as it is currently one of the most widely used approaches to degree semantics.

\subsection{Semantic type of degree expressions}

In this section, the semantic type of degree gradation is discussed. In 5.2.1, I will discuss the question whether gradation has to be conceived of as quantification or rather as modification. A classification of different types of degree expressions is presented in 5.2.2.

See Naumann (2014) for an integration of phase quantification within the frame approach of Löbner (2012a, 2014). 


\subsubsection{Quantification vs. modification}

In chapter 2, the question emerged whether there is a deeper connection between gradation and quantification. The question has been raised by examples like those in (17). As demonstrated, German viel can be used for adverbial extent gradation as well as to indicate a nominal quantity. Examples such as (17b) are conceived by many authors as falling under the notion of 'quantification.'
a. Er schläft viel.
he sleeps much
'He sleeps a lot.'
b. viele Bücher
much books
'many books'

Bosque \& Masullo (1998) extend the notion of 'quantification' to all instances of normally adnominally used quantity expressions like mucho 'a lot' or un poco 'a bit' in Spanish. In their view, examples like (18), taken from Spanish, are considered to be instances of 'inherent quantification.'

$$
\begin{aligned}
& \text { Me gusta un poco. } \\
& \text { cL.to.me like a bit } \\
& \text { 'I like it a little bit.' } \\
& \text { (Gallego \& Irurtzun, 2010, 5) }
\end{aligned}
$$

In chapter 4 , I concentrated on the syntactic status of adnominal quantity expressions and argued for treating them as adjectives rather than quantifiers. The aim of the current section is to discuss the semantic type of degree expressions, focusing on their adverbial uses. Two different questions arise regarding the semantic type of (adverbial) degree expressions: (i) of which type can (adverbial) degree expressions be? and (ii) are all (adverbial) degree expressions of the same semantic type?

de Swart (1993) distinguishes between two basic types of adverbs; they are either quantifiers or modifiers. She is working in the format of Generalized Quantifier Theory (GQT, Barwise \& Cooper 1981) which analyses determiners like much or many as two-place expressions. Each such determiner takes two set denoting expressions (which are of type 
$\langle e, t\rangle)$ as its arguments and makes a predication about the intersection of both sets. Hence, determiners are of the semantic type $\langle\langle e, t\rangle\langle\langle e, t\rangle, t\rangle\rangle$ and are generalized quantifiers.

Following de Swart $(1993,5)$, the function of quantificational adverbsis to indicate a quantity of events. This is opposed to the semantic function of adverbial modifiers, which do not indicate a quantity of events but add a "further specification to the identity of the event itself" (de Swart, 1993, 5). Modifiers take an unsaturated expression and form another unsaturated expression of the same type (McNally, to appear, 2) ${ }^{8}$ Hence, they are of the semantic type $\langle\mathrm{X}, \mathrm{X}\rangle$, whereby $\mathrm{X}$ can be any simple or complex type. ${ }^{9}$ De Swart states that (adverbial) modifiers map sets onto subsets. This is illustrated by example (19) where an entailment relationship between the sentences fohn runs fast and fohn runs holds. If John is running fast, he necessarily is running. The situations in which he is running fast form a subset of those situations in which he is running.

John runs fast. $\Rightarrow$ Fohn runs.

Following de Swart, quantificational adverbs differ from manner adverbs like fast. She discusses the sentences in (20) and says that if the sentence in (a) is true, the one in (b) is true too but "the relation [between the sentences] is not an implicational one [...]. We cannot claim that Anne's going to the movies [often] is a subset of Anne's going to the movies." (de Swart, 1993, 5).

(20) a. Anne est souvent alleé au cinema.

Anne is often gone to.the cinema

'Anne has often been to the movies.'

b. Anne est alleé au cinema.

Anne is gone to.the cinema

'Anne has been to the movies.'

(de Swart, 1993, 5)

$8 \quad$ Also see the discussion of the notion of 'modifier' in Morzycki (2013), who advocates the view that modification is not a unitary concept (p. 262).

As Wunderlich (1997) and McNally (to appear), among others, show, not all modifiers are of the semantic type $\langle\mathrm{X}, \mathrm{X}\rangle$. 
In (21a) and (b), souvent 'often' and beaucoup indicate the frequency of Jean's going to the movies. Both sentences are truth conditionally equivalent and therefore beaucoup in its use as extent intensifier could be conceived of as an adverb of quantification. Following de Swart's argumentation, the situation where Jean goes to the movies a lot should also not form a subset of those situations where Jean goes to the movies. Beaucoup used as an expression for degree gradation differs from its extent use. In (22), we have the same entailment relationship between the sentences as observed for the manner adverb in (19).
a. Jean va souvent au cinema. Jean goes often to.the movies 'Jean often goes to the movies.'
b. Jean va beaucoup au cinema. Jean goes a lot to.the cinema 'Jean goes to the movies a lot.'

Il aime beaucoup cette langue. $\Rightarrow$ Il aime cette langue. he loves a lot this language he loves this language 'He loves this language very much. $\Rightarrow$ He loves this language.'

It is doubtful whether de Swart's characterization of the relationship between the sentences in (21), and therefore those in (22) too, is correct. It is the case that the situations where (21a) is true form a subset of those situations where (21b) is true. Hence, (21a) entails (21b); if one has gone to the movies often, it must be the case that one has gone to the movies. What de Swart wants to say is that beaucoup in its extent use is not a modifier of the event, whereas beaucoup in its degree use really functions as a modifier analogous to manner adverbs. De Swart also claims that extent beaucoup, like the frequency adverb souvent, is an adverbial quantifier. If this is true, beaucoup would be ambiguous between functioning as adverbial quantifier and degree modifier. Abeillé et al. (2004), based on the work of de Swart (1993) and Doetjes (1997), argue against such an ambiguity. Adverbs of quantification show scope ambiguities and license two different readings: a 'relational' and a 'non-relational' one de Swart (1993). De Swart argues that only the relational reading requires a quantificational analysis similar to the distinction between 'cardinal' and 'proportional' readings of adnominal quantity expressions. In (23), (i) is the relational reading of 
souvent, whereas (ii) indicates the non-relational reading. In the relational reading of the example, the quand clause provides the restriction for the adverbial quantifier, whereas the subordinated sentence functions as the domain of quantification in the non-relational use.

Quand elle est à Paris, Pauline va souvent au Louvre. when she is in Paris Pauline goes often to.the Louvre (i) 'Many of the times she is in Paris, Pauline goes to the Louvre.'

(ii) 'Whenever she is in Paris, Pauline often goes to the Louvre.' (Abeillé et al., 2004, 191)

The cardinal reading of (24) is that a high number of third-year students signed up, whereas the proportional reading is that a high number of all the third-year students signed up. The proportional reading allows for a partitive paraphrase like many of the third-year students signed up for class, whereas the cardinality reading does not (cf. Löbner 1987b, 192).

Many third-year students signed up for class.

Partee (1988), too, argues that adnominal quantity expressions like many are ambiguous between a quantificational use, which leads to the proportional reading, and an adjectival use that licenses the cardinal reading. ${ }^{10}$ In the latter use, quantity expressions are similar to cardinal numbers, with the only difference being that the first-mentioned are vague and contextdependent, the latter are not. Partee argues for a type ambiguity of adnominal quantity expressions, only the proportional use giving rise to a quantificational analysis. Hoeksema (1983); Löbner (1987a,b, 1990) and Solt $(2009,2011)$ argue against an ambiguity analysis and assume that quantity expressions never require a quantificational analysis. ${ }^{11}$ What is relevant at this stage is that de Swart's argumentation regarding adverbs of quantification resembles Partee's argumentation regarding the type ambiguity of adnominal quantity expressions: only proportional/relational readings require a quantificational analysis, whereas cardinal/non-relational ones do not.

$\overline{10}$ Partee does not explicitly state whether it is a lexical or contextual ambiguity but only writes that "the ambiguity has both syntactic and semantic repercussions" (Partee, 1988, 384f.).

11 See the mentioned literature for the details of the argumentation and an explanation of how the difference between the proportional and the cardinal reading results. 
Abeillé et al. (2004) show that extent beaucoup only allows for a nonrelational interpretation (25). ${ }^{12}$ The authors take this contrast between souvent and beaucoup as an argument against a quantificational analysis of the latter.
Quand il est à Paris, Paul va beaucoup au Louvre. when he is in Paris Paul goes a lot to.the Louvre 'Whenever he is in Paris, Paul goes to the Louvre a lot.'
(Abeillé et al., 2004, 191)

I follow Abeillé et al. (2004) in rejecting a GQT analysis of extent degree expressions but this does not necessarily mean that such degree expressions are modifiers. As a further option, such expressions could function as argument saturating expressions. Such an analysis is proposed by Kennedy $\&$ McNally (2005a). In their analysis, degree expressions are of the type $\langle\langle$ d, $\langle e, t\rangle\rangle,\langle e, t\rangle\rangle$ and saturate the degree argument of a gradable expression. In a different work, Kennedy \& McNally (2005b) argue that not all degree expressions are of the same semantic type, some are argument saturating, whereas others are plain modifiers. The classification of degree expressions regarding their semantic type is discussed in some detail in the next section.

\subsubsection{Classification of degree expressions}

The starting point for Kennedy \& McNally's (2005b) subclassification of degree expressions are examples like those in (26). In these sentences, multiple degree expressions are used. (26a), for example, uses the measure phrase 10 feet for a further modification of the comparative construction and it specifies the degree to which the new tower exceeds the height of the Empire State Building.
a. a new tower 10 feet taller than the Empire State Building
b. an old department store a lot less taller than the city hall build- ing
c. an engineer very much more afraid of heights than the architect (Kennedy \& McNally, 2005b, 178)

Fortuin $(2008,239)$ shows that the same contrast observed between souvent and beaucoup obtains between Russian často 'often' and mnogo 'much'. 
The examples in (27) further show that degree expressions, in this case we have a combination of quite and very in (a) and of rather and very in (b), can be stacked.

a. He specializes in swimwear and is quite very popular for it.

b. Lola rennt, or Run Lola Run in English, is the first German film I've ever seen. It's rather very inventive.

(Kennedy \& McNally, 2005b, 180)

If degree expressions are of the semantic type $\langle\langle\mathrm{d},\langle\mathrm{e}, \mathrm{t}\rangle\rangle,\langle\mathrm{e}, \mathrm{t}\rangle\rangle$, as Kennedy $\&$ McNally (2005a) state, then the stacking of degree expressions cannot be easily explained. Going back to (26a), the comparative morpheme takes a gradable adjective (type $\langle\mathrm{d},\langle\mathrm{e}, \mathrm{t}\rangle\rangle$,) as its argument and returns an expression of type $\langle e, t\rangle$. But this would be of the wrong input type for the measure phrase 10 feet, which also requires an argument of type $\langle\mathrm{d},\langle\mathrm{e}, \mathrm{t}\rangle\rangle$. The same is true for the other examples in (26) and (27).

At the same time, restrictions regarding the order of stacked degree expressions can be found. As the examples in (28) show, the order (very) much $>$ more is possible, whereas more $>$ (very) much is not.
a. This new building will give the university (very) much more ef- fective support.
b. *This new building will give the university more (very) much ef- fective support.

(Kennedy \& McNally, 2005b, 181)

Kennedy \& McNally claim that these data can best be explained by assuming that different classes of degree expressions exist, which are of different semantic types. The different classes of degree expressions are summarized in figure 11.

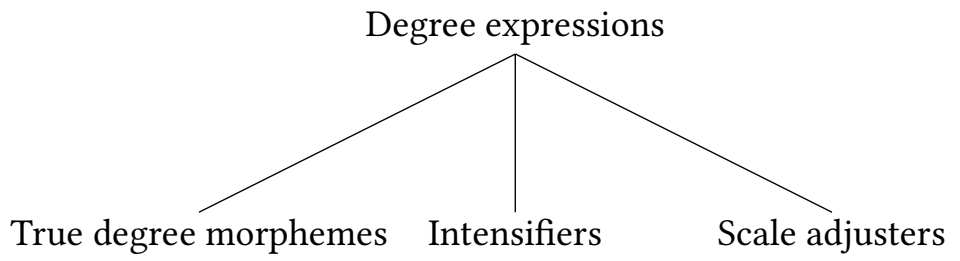

Figure 11: Types of degree expressions Kennedy \& McNally (2005b). 
The class of 'true degree morphemes' includes measure phrases as well as the positive morpheme. These expressions are of the type $\langle\langle\mathrm{d},\langle\mathrm{e}, \mathrm{t}\rangle\rangle,\langle\mathrm{e}$, $t\rangle$ and fit Kennedy \& McNally's (2005a) analysis of degree expressions. They saturate the degree argument and thereby change the semantic type of its argument. The second class are 'intensifiers' like very. Kennedy \& McNally take intensifiers to be predicate modifiers, which apply to expressions that have an already saturated degree argument. The semantic function of intensifiers is to manipulate the standard introduced by the positive morpheme (Kennedy \& McNally, 2005b, 183). As mentioned in the last section, the comparison class for very consists of those individuals for which the positive form of the respective predicate is true. Hence, very combines with the adjective after its degree argument is saturated by the positive morpheme. Since the composition of the positive morpheme and an adjective result in an expression of type $\langle e, t\rangle$, intensifiers are of type $\langle\langle e, t\rangle,\langle e$, $t\rangle)$. The comparative is a 'scale adjuster,' which manipulates the measure function of an adjective. In the case of the comparative, a minimal scale value is introduced. Kennedy \& McNally (2005a) assume that in the case of a comparative a new scale is derived by introducing a derived minimal scale value, which is the degree of the comparandum. Hence, comparatives can be considered as functions from measure functions to measure functions and since measure functions are of the type $\langle\mathrm{d},\langle\mathrm{e}, \mathrm{t}\rangle\rangle$, scale adjusters are of type $\langle\langle\mathrm{d},\langle\mathrm{e}, \mathrm{t}\rangle\rangle,\langle\mathrm{d},\langle\mathrm{e}, \mathrm{t}\rangle\rangle\rangle$.

Only intensifiers and scale adjusters are true modifiers since modifiers take an unsaturated expression as its argument and return an unsaturated expression of the same type (cf. McNally to appear). This means that modifiers do not change the type of its argument, which is not the case for true degree morphemes, as they are argument saturating expressions. That intensifiers and scale adjusters are modifiers is supported by the fact that "a number of combinations of multiple intensifiers [and scale adjusters] are possible," (Kennedy \& McNally, 2005b, 186) meaning that they allow stacking. ${ }^{13}$ This is shown for (29) where multiple comparatives are combined.

a. Dole isn't as much more conservative than Clinton as Buchanan is.

13 For further examples of comparative stacking, see Bhatt \& Pancheva (2004, 4n6). 
b. Maverick's is more too dangerous to surf than it was yesterday. ${ }^{14}$ (Kennedy \& McNally, 2005b, 186)

The examples in (30) show stacking of degree expressions in German. So 'so' introduces an equative construction and allows for a deicitic as well as non-deicitic use (b). In the latter case, a subordinated sentence indicates the compared degree. $Z u$ 'too' in (c) introduces an excessive construction, expressing that the respective degree is too high for some purpose. In both cases, the equative/excessive element precedes sehr. ${ }^{15}$
a. Er blutet so sehr.
he bleeds so very
'He is bleeding so much.'
b. Er ist so groß, dass er nicht durch die Tür passt. he is so tall that he not through the door fits 'He is so tall that he does not fit through the door.'
c. Er schluchzt zu sehr, um sprechen zu können. he sobs too very for speak to can 'He is sobbing too much to speak.'

The constructions in (30) differ from ordinary degree constructions with sehr in being not factitive anymore (Ropertz, 2001, 5). Although being sehr gro $\beta$ 'very tall' entails being gro $\beta$ 'tall,' such an entailment does not apply to (30a) and (b), as Ropertz points out. That someone sobs too much does not mean that he also sobs much. Hence, $z$ u sehr schluchzen 'sob too much' does not entail sehr schluchzen 'sob much.'

In (31) we have stacking of two intensifiers which further specify the difference degree expressed by the comparative. First, viel indicates that the difference in size between the brothers is large and then sehr further indicates that it is not only large but very large. The addition of sehr does not affect the factitivity of the construction, being sehr viel größer 'very much taller' entails being viel größer 'much taller.'

\footnotetext{
$14 \quad$ Several native speakers I consulted did not accept the sentences in (29). For the sake of the argument, I follow Kennedy \& McNally's judgements of the sentences' acceptability.

15 See Löbner (1990) for a deeper discussion of these degree constructions.
} 
Der funge ist sehr viel größer als sein Bruder. the boy is very much taller as his brother 'The boy is really a lot taller than his brother.'

There is much more to say regarding the combination of multiple degree expressions as they show more restrictions than those discussed in this section. But a deeper discussion of this topic would go beyond the scope of the current thesis. The relevant point of the discussion is to indicate the heterogeneity of degree expressions with respect to their semantic type. This entails that the different types of degree expressions enter the compositional process at different stages. Scale adjusters are the first degree expressions that combine with gradable adjectives, as they are functions from measure functions to measure functions. True degree morphemes take measure functions as their arguments and saturate the degree argument. Intensifiers enter the compositional process after the degree argument has been saturated. In the remaining discussion, I am focusing on intensifiers as defined above. The term 'degree expression' will be used as a general term for gradation devices.

\subsection{Semantics of intensifiers}

This section aims at discussing the semantics of the intensifiers sehr and very. In this section, I am concentrating on adjectival degree modification and turn to the discussion of verbs in section 5.4. A crucial property distinguishing between intensifiers is factivity (Bierwisch 1989; Löbner 1990), also called 'extensionality' by Piñón (2005) or evaluativity (Neeleman et al. 2004; Rett 2007). Factivity is exemplified by the examples in (32) taken from Piñón $(2005,153)$.
a. Rebecca completely solved the problem. $\Rightarrow$ Rebecca solved the problem.
b. Rebecca partly (half) solved the problem. $\nRightarrow$ Rebecca solved the problem.

Piñon states that dropping completely preserves the truth of the predication, whereas dropping partly/half does not. Or to put it another way, completely requires the truth of the embedded predication (to solve the problem), 
whereas partly/half require that the embedded predication is not true. Sehr - but the same holds for its correspondents in other languages - is also factitive, meaning that it requires the embedded predication to be true. If, as in example (33), a boy is sehr gro $\beta$ 'very tall,' it entails that he has to be gro $\beta$ 'tall.' You cannot be 'very tall' without being 'tall.' This is shown in (34), where the negation of being tall leads to a contradiction.

Der funge ist sehr groß. $\Rightarrow$ Der funge ist groß.

the boy is very tall the boy is tall

'The boy is very tall. $\Rightarrow$ The boy is tall.'

(34) \#Der funge ist sehr groß, aber er ist nicht groß.

the boy is very tall but he is not tall

'The boy is very tall but he is not tall.'

Factivity is an important property of sehr since on the one hand it requires the truth of the embedded predicate; on the other hand, it determines at which part of the scale the intensifier induces a partitioning. Following Löbner (1990, 2012b, 233) and Ropertz (2001, 21) the partitioning of the scale induced by sehr can be illustrated as in figure 12 .

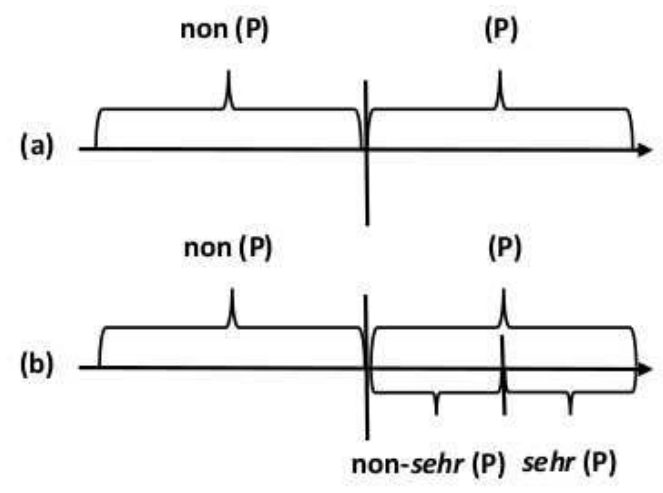

Figure 12: Scale partitioning by an ungraded gradable relative predicate (a) and by one graded by sehr (b).

In (a), the partitioning of a scale induced by a gradable relative predicate $P$ like groß 'tall' is shown. The adjective applies to a height scale and separates those degrees for which gro $\beta$ is true, in the respective context, and 
those for which it yields a false predication, i.e. for which non $(P)$ is true. As shown in (b), sehr applies to the part of the scale for which the predicate is true and separates between those individuals which are sehr gro $\beta$ 'very tall' and those which are gro $\beta$ but not sehr gro $\beta$, i.e. for which non-sehr gro $\beta$ is true.

Factivity does not only hold for adadjectival sehr but similarly for its adverbial use, as stated by Löbner (2012b, 234) and illustrated in (35). If someone wächst sehr 'grows a lot', he has to wachsen 'grow' at all, hence sehr wachsen entails the truth of wachsen.

$$
\begin{aligned}
& \text { Das Kind ist sehr gewachsen. } \Rightarrow \text { Das Kind ist gewachsen. } \\
& \text { the child is very grown child is grown } \\
& \text { 'The child has grown a lot. } \Rightarrow \text { The child has grown.' }
\end{aligned}
$$

The fact that sehr is factive and leads to a partition between 'non-high' and 'high' degrees imposes restrictions on graded predicates. An ungraded predication has to be true for at least two degrees otherwise a partitioning of degrees is impossible. Kennedy \& McNally (2005a) do not explicitly discuss factivity for very but base their analysis of the intensifier on that property as the following quote shows: "whereas the regular contextual standard [for the ungraded adjective] is a degree that exceeds a norm or average of the relevant property calculated on the basis of an arbitrary, contextually determined comparison class, the very standard is a norm or average calculated in the same way but just on the basis of those objects to which the unmodified predicate truthfully applies" (Kennedy \& McNally, 2005a, 369f.). It follows that an ungraded but gradable adjective and one graded by very apply to two different domains. An adjective like big applies to all entities that have some size, whereas very big applies only to those for which - in a certain context - big is true. This is what is illustrated in figure 12 and it also was the reason to claim in section 5.2 that intensifiers enter the compositional process only after the gradable predicate's degree argument has been saturated. Saturation of the degree argument is required to decide whether the ungraded predicate is true of an individual or not and this is what is presupposed by very, sehr and similar degree expressions.

Based on the proposal in Kennedy \& McNally (2005a, 370), the denotation of very can be represented as in (36). Very takes two arguments, a 
gradable property $g$ and an individual $x$ and expresses that the degree of $x$ in $g$ exceeds the standard of comparison. The standard for very depends on the standard of the positive form of $g$. (36) states that very $A$ is true of $x$, if the degree of $x$ in the property $g$ exceeds the standard for the ungraded positive form of $A$. This ensures factivity of the construction very $A$.

$$
\llbracket \operatorname{very} \rrbracket=\lambda \mathrm{g} \lambda \mathrm{x} \cdot(\mathrm{g}(\mathrm{x})>\mathbf{s}(\lambda \mathrm{y} \cdot \llbracket \operatorname{pos}(\mathrm{g}(\mathrm{y})) \rrbracket)
$$

In (37), it is shown how very combines with the gradable adjective tall. First, the adjective combines with pos to convert the measure function into a property of individuals and then very applies to the positive form.

$$
\begin{aligned}
& \llbracket \operatorname{tall} \rrbracket=[\lambda \mathrm{x} \cdot \operatorname{tall}(\mathrm{x})](\llbracket \operatorname{pos} \rrbracket) \\
& \llbracket \operatorname{pos}[\operatorname{tall}] \rrbracket=[\lambda \mathrm{x} \cdot \operatorname{tall}(\mathrm{x})] \geq \mathbf{s}(\operatorname{tall})](\llbracket \operatorname{very} \rrbracket) \\
& \llbracket \operatorname{very}[\operatorname{pos}[\operatorname{tall}]] \rrbracket=[\lambda \mathrm{x} \cdot \operatorname{tall}(\mathrm{x})]>\mathbf{s}(\lambda \mathrm{y} \cdot \operatorname{tall}(\mathrm{y}) \geq \mathbf{s}(\text { tall }))]
\end{aligned}
$$

Regarding the truth conditions of very, Kennedy \& McNally write: "Thus very is true of an object if the degree to which it is $A$ exceeds a norm or average of the $A$-scale for a comparison class based on those objects that have the property of pos $A$ in the context of utterance" (Kennedy \& McNally, 2005a, 370). The effect of very is to raise the standard to a 'high' degree on the respective scale. What counts as a 'high' degree is contextdependent. In (38a), it is expressed that the size of the tree has increased a lot, whereas in (b) it is stated that the height of the boy increased by a large degree. Whatever counts as a large degree in these situations is dependent on the respective comparison class. An increase in size by one centimeter in a month could be a lot for a child of a certain age but not for a tree (or vice versa). As the comparison class and therefore also the respective standard is dependent on the argument of the gradable property, this type of context-dependency is part of the calculation of the standard of comparison.
a. Der Baum ist sehr gewachsen. the tree is very grown 'The tree has grown a lot.'
b. Der funge ist sehr gewachsen. the boy is very grown 'The boy has grown a lot.' 
Kennedy \& McNally argue at length that very only modifies relative adjectives but not absolute ones. The reason is that absolute adjectives restrict the standard to an endpoint of the scale and it would have no semantic effect adding very as it could not further raise the standard (cf. Kennedy \& McNally 2005a, 372). In their analysis, Kennedy \& McNally also mention apparent counterexamples like This region of the country is very dry (Kennedy \& McNally, 2005a, 371), in which case the absolute adjective $d r y$ is interpreted as being a relative one. In their view, dry only allows for a relative reading if it denotes a permanent and stable property but has an absolute reading if it denotes a transient property. The authors remain uncommitted as to whether this is a case of polysemy, vagueness regarding the adjectival standard or coercion. What is essential is merely the fact that both readings, the relative and the absolute one, can be disambiguated. There are similar examples in German, as discussed by Ropertz (2001, 28f.). One case is the adjective leer 'empty,' which, as shown in (39a), is compatible with an endpoint modifier but also with sehr (b). In the first case, the sentence means that nobody or nothing is in the theater. This is not the interpretation of (b), which rather means that the theater is not only empty, compared to some standard of comparison, but rather empty to a high degree. This relative reading of leer does not entail that nobody or nothing is in the theater but that the number of persons or things is less compared to, for example, some expectation.
a. Das Theater ist vollständig leer.
the theater is completely empty
'The theater is completely empty.'
b. Das Theater ist sehr leer.
the theater is very empty
'The theater is very empty.'

The discussion on the distribution of degree expressions always presupposes that sehr/very and endpoint modifiers such as vollständig/completely are in complementary distribution. This is true in many cases, such as those in (40) and (41). Groß 'tall' rejects the endpoint modifier but takes sehr, whereas the adjectival participle geschlossen 'closed' takes the endpoint modifier but rejects sehr. 
(40)
a. Das Kind ist sehr groß.
the child is very tall
'The child is very tall.'
b. \#Das Kind ist vollständig groß.
the child is completely tall
'The child is completely tall.'
(41) a. Die Tür ist vollständig geschlossen.
the door is completely open
'The door is completely open.'
b. \#Die Tür ist sehr geschlossen.
the door is very open
'The door is very open.'

If one assumes that very/sehr and completely/vollständig are in complementary distribution, examples like (39) are in need of an explanation. But one could also argue that it is only an apparent complementary distribution. I assume that there are at least two types of maximal absolute adjectives: adjectives that are only true at the maximal value of the scale and adjectives that truthfully denote the region adjacent to the maximal scale value (including the maximal scale value). Geschlossen 'closed' would only be true at the maximal degree on the respective scale, whereas voll 'full' would yield a true predication if the degree falls within a range before the maximal scale value. This distinction can be substantiated by two linguistic differences between the two types of adjectival predicates. In (42) it is shown that voll 'full' allows for a comparative construction, whereas geschlossen 'closed' does not. The examples in (43) show that the positive use of voll is compatible with the statement that a still higher degree could be achieved, which is not possible for geschlossen.
a. Dieses Glas ist voller als das andere. this glass is fuller than the other 'This glass is fuller than the other one.'
b. \#Diese Tür ist geschlossener als die andere. this door is more.closed than die other 'This door is more closed than the other one.' 
a. Das Glas ist voll, aber es könnte noch voller sein. the glass is full, but it could still fuller be 'The glass is full but it could be even fuller.'

b. \#Die Tür ist geschlossen, aber sie könnte noch geschlossener the door is closed but she could still more.closed sein.

be

'The door is closed but it could be even more closed.'

The distinction between 'endpoint' and 'end range' absolute adjectives is crucial for the analysis of degree gradation of change of state verbs in the next chapter. This distinction allows predicting which telic change of state verbs admit degree gradation and which reject it. Hence, I take a different stance on the restrictions of intensifiers like very, sehr with respect to scale structure. As long as the adjective denotes more than a single degree on the scale, a standard raising effect of intensifiers such as very or sehr should be possible irrespective of whether the scale is closed or not.

\subsection{Degrees, scales, and verbs}

So far, the discussion of degree gradation has centered around adjectives and intensifiers of adjectives. The question of the current section is whether the analysis of gradable adjectives can easily be extended to gradable verbs. In their analysis of gradable adjectives, Kennedy \& McNally (2005a) assume measure functions to be the semantic core of gradable relative and absolute adjectives. A central assumption of this approach is that degree morphology is required to turn measure functions into predications of individuals. Degree morphology, like the pos morpheme, introduces a standard of comparison by saturating the degree argument of the adjective.

Gradable adjectives can be conceived of as scalar predicates par exellence as they directly express a scalar predication. The adjective wide, for example, is a function that returns the width degree of its argument and compares it to a standard of comparison. Closely related to gradable adjectives are deadjectival change of state verbs like widen. Such verbs express a scalar change of state and will be discussed in more detail in chapter 6 . 
But there is also another class of verbs that is similar to gradable adjectives; namely scalar stative dimensional verbs Gamerschlag (2014). Stative dimensional verbs lexically encode a single dimension; in (44), examples of scalar (a) and non-scalar stative dimensional verbs (b) are shown.
a. The book costs ten dollars.
b. She is called Ava.

(Gamerschlag, 2014, 275f.)

The verb cost encodes the dimension PRICE, the measure phrase ten dollars is required as an argument of the verb. Cost equates the price of the book with the price denoted by the measure phrase. PRICE is a scalar dimension, as its values are linearly ordered. Be called encodes the non-scalar dimension NAME (for the distinction between scalar and non-scalar dimensions see chapter 2.2). Ava functions as an argument of the verb and specifies the value of the dimension encoded in the verb.

An external value specification by an argument-like NP is not required in each case as some verbs allow absolute uses (45). In (a) the value of the weight of the suitcase is specified externally by the measure phrase zehn Kilo 'ten kilos.' (45b) illustrates the absolute use; in which case it expresses that the suitcase has a contextually 'high' degree of weight (see Gamerschlag 2014 for a more extensive discussion of absolute uses of stative dimensional verbs).
a. Der Koffer wiegt zehn Kilo.
the suitcase weighs ten kilo
'The suitcase weighs ten kilos.'
b. Der Koffer wiegt.
the suitcase weighs
'The suitcase weighs a lot/is heavy.'

(Gamerschlag, 2014, 283)

In the absolute use, weigh makes a scalar predication, as it expresses that the degree on the scale exceeds some context-dependent standard. This shows that the scalar predication is not only invoked by a degree expression but it is really anchored in the lexical semantics of the verb. Therefore, a semantic representation for wiegen 'weigh' can be proposed, as in (46). 


$$
\text { 【wiegen } \rrbracket=\lambda \mathrm{d} \lambda \mathrm{x} \lambda \text { v.weight }(\mathrm{x}, \mathrm{v}) \geq \mathrm{d}^{16}
$$

There are two reasons to assume a degree argument for wiegen and other scalar stative dimensional verbs. First, in its absolute use the verb requires an external value specification in terms of a measure phrase. Hence, there is an argument slot for this type of expression. Second, in their absolute use, scalar stative dimensional verbs express a comparison of the degree of its argument and a context-dependent standard. A scalar predication also arises if no explicit degree construction is used. For the absolute use, one can assume existiential binding of the degree argument. Following the analysis of Kennedy \& McNally (2005a), one could also propose a verbal positive morpheme that saturates the degree argument in the absolute use. But as far as I know, there is no evidence for an overt expression of such a verbal morpheme in any language (in contrast to the overt expression of adjectival pos in Sinitic languages). Due to the absence of linguistic evidence for verbal pos, I will not assume such a null morpheme for scalar verbs in contrast to Kennedy \& Levin (2008).

The discussion reveals that there are some verbs which express a scalar predication in all of their uses. But verbal degree gradation is not restricted to these verbs and (to be more precise) not all scalar stative dimensional verbs accept intensifiers. Some of them take viel 'much' as an intensifier but reject sehr (47), others license neither (48). For dauern 'to last', the adjective lang 'long' is used for indicating a 'high' degree and therefore blocks the use of more general degree expressions like sehr or viel.
a. Der Koffer wiegt viel/*sehr. the suitcase weighs much/very 'The suitcase weighs a lot.'
b. Das Buch kostet viel/* sehr. the book costs much/very 'The book costs a lot.'

$$
\begin{aligned}
& \text { Der Film dauert * } \text { viel }^{*} \text { sehr/lang. } \\
& \text { the film lasts much/very/long } \\
& \text { 'The film lasts a long time.' }
\end{aligned}
$$

\footnotetext{
$16 \quad$ I use ' $v$ ' as a variable for eventualities, covering both states and events. 'e' is used for events if the respective verb is clearly eventive.
} 
Many gradable verbs belong neither to the class of change of state verbs nor to the class of scalar stative dimensional verbs. Two examples are the verbs stinken 'stink' and regnen 'rain.' Degree gradation of stinken (49a) results in a specification of the degree of the intensity of the emitted smell. With regard to regnen, it is the quantity of the emitted rain that is specified by the intensifier (49b).
a. Der Hund stinkt sehr. the dog stinks very 'The dog really stinks.'
b. Gestern hat es sehr geregnet. yesterday has it very rained 'Yesterday, it rained a lot.'

The ungraded verb regnen in (50) only expresses the emission of rain but does not make a predication about the quantity of rain. Hence, the quantity scale, to which sehr applies, is not an active meaning component of regnen in each context of use. It is clearly the case that if it is raining, some quantity of rain must be emitted but this does not entail that the ungraded verb makes a predication about the quantity of emitted rain. Rather, the quantity of emitted rain is only relevant in a gradational context.

$$
\begin{aligned}
& \text { Gestern hat es geregnet. } \\
& \text { yesterday has it rained } \\
& \text { 'Yesterday, it rained.' }
\end{aligned}
$$

The same argumentation holds for stinken. Clearly, it is the case that if a dog stinks, the emitted smell needs to have some intensity as it is not possible to have smell without any intensity. But with regnen, the ungraded verb does not make a predication about the degree of the intensity of the emitted substance. If the verb did this, a sentence like (51) would always contain an (implicit) comparison between the intensity of the smell of the dog and some standard for the intensity of stinking.

(51) Der Hund stinkt. the dog smells 'The dog smells.' 
We do not interpret a sentence like (51) with respect to an (implicit) comparison class like 'the dog smells for a dog,' 'the dog smells more than a standard dog smells' or 'the dog smells more than he normally smells.' Given these facts, there is no reason to conclude that the measure functions QUANTITY or INTENSITY are active meaning components of these verbs in sentences like (50) and (51). I propose the definition in (52) for the notion of a 'lexically scalar verb':

(52) Lexically scalar verb: A verb is lexically scalar iff it expresses a scalar predication in every context of use.

As argued above, wiegen 'weigh' is a lexically scalar verb, as it provides a comparison between the weight of its argument and some other degree of weight. Another class of lexically scalar verbs are change of state verbs, as discussed in 3.3. But note that the definition proposed in (52) does not rely on Rappaport Hovav's characteristics of scalar verbs, as they would not be appropriate for stative verbs like wiegen. Stinken, as the discussion above revealed, is a lexically non-scalar verb that does not encode a scale in its lexical semantics. Rather stinken and lexically non-scalar verbs in general require an explicit degree context for expressing a scalar predication.

Even if verbs like stinken are lexically non-scalar, it is not arbitrary that sehr indicates the intensity of the emitted smell in (49a) but the quantity of the emitted rain in (49b). The verb determines the respective scale which is 'activated' if required by the (linguistic) context. Activation of attributes is not a process of coercion as the meaning of the verb is not shifted to fit the context. Rather, the meaning is enriched by a gradable attribute.

A neo-Davidsonian representation of the lexical semantics of stinken is shown in (53). The representation consists of five conjuncts, the first one is a predicate of the eventuality argument. The next two other conjuncts link the explicit and implicit event participants to the eventuality. EMITTER links the emitter argument, which is the only syntactic argument of the verb, to the eventuality. EMITTEE represents an implicit semantic argument of the verb, namely the stimulus emited in the eventuality. ${ }^{17}$ The emitee is specified as being smell and being unpleasant by the predicates in the last two conjuncts.

17 The notion of an 'implicit argument' is discussed in more detail in chapter 7. 


$$
\begin{aligned}
& \llbracket \text { stinken } \rrbracket=\lambda \mathrm{x} \lambda \mathrm{v} \exists \mathrm{y} \cdot \operatorname{emit}(\mathrm{v}) \wedge \operatorname{EMITTER}(\mathrm{v})=\mathrm{x} \wedge \operatorname{\operatorname {EMITTEE}}(\mathrm{v})=\mathrm{y} \\
& \wedge \operatorname{smell}(\mathrm{y}) \wedge \text { unpleasant }(\mathrm{y})
\end{aligned}
$$

EMITTER and EMITTEe are attributes in the sense of frame theory (Petersen 2007; Löbner 2014). This notion of 'frame' is based on Barsalou's (1992a; 1992b) frame account and differs from the one employed by Fillmore (1968), for example. The frame theory proposed by Löbner uses recursive attribute-value structures for representing lexical and conceptual meaning. What is essential is the notion of 'attribute,' which comprises partial functions that assign a unique value to its argument (Löbner, 2014, 26f.). As he states: "Value specifications may be more or less specific, but at the most specific level of description, the value is uniquely determined" (Löbner, 2014, 26.). In the following, all attributes are written in small capitals. The attribute EMITTER takes the eventuality and returns the individual that bears the emitter role in that eventuality. Similarly, for the attribute EMITTEE which returns the individual that functions as emittee in the respective eventuality. Such role attributes are functional; for each eventuality there is only one emitter, emittee, agent or theme respectively. ${ }^{18}$ I integrate attributes in a neo-Davidsonian account of verb semantics and do not use a frame-based representation since up to now no well-established frame approach to verb meaning exists. Nevertheless, there have been some attempts to represent verbal concepts in frames (e.g. Kallmeyer \& Osswald 2013; Gamerschlag et al. 2014; Fleischhauer et al. 2014; Fleischhauer 2015; Kawaletz \& Plag 2015).

Gradable properties are also attributes in the sense discussed above. But InTENSITY is not an attribute in the lexical entry of the verb stinken. Rather, the attribute is retrieved from the conceptual knowledge associated with the (implicit) emittee argument stink. Part of our conceptual knowledge associated with the nominal concept stink is 'is emitted by something/someone,' 'has a certain aroma,' 'has a certain intensity.' The central idea is that lexical representations can be enriched by additional attributes if this is required by the linguistic context. With respect to verbal degree gradation, this idea can be spelled out as follows: an intensifier requires a gradation scale, and if there is no scale in the lexical representation of the

18 See Löbner (2014, 42ff.) for an analysis of semantic roles as attributes in the sense of frame theory. 
verb, a suitable scale has to be retrieved from the conceptual knowledge associated with the verb. The verb is not arbitrarily linked to conceptual knowledge, but only components that are part of the verb's lexical semantics give access to conceptual knowledge. With regard to the representation in (52), only the attribute specified in the lexical entry gives access to conceptual knowledge. As only the implicit EMITTEE argument is specified, it is only stink that allows the activation of concrete conceptual knowledge and hence it is only possible to retrieve a gradable property from the knowledge about stink. Since the intensifier combines with the verb before the syntactic arguments are saturated (cf. chapter 4), the EMITTER attribute does not license access to conceptual knowledge as it is unspecified. Hence, the lexicalized meaning components constrain the possible attributes that can be activated, and therefore the lexical meaning of the verb constrains activation of suitable gradation scales. Based on this discussion, it is possible to give a more precise characterization of the notion of 'degree gradable verb': a verb admits degree gradation if it either lexicalizes a suitable gradation scale or if the activation of a suitable gradation scale is licensed by the conceptual knowledge associated with a meaning component lexically specified in the verb.

But it is not always the case that degree gradation specifies the degree of a gradable property of an implicit argument of the verb. An example where this is not the case is (54). The gradable property is DIFFERENCE of the subject referent's size at two different points in time and therefore the argument of the measure function is a syntactic argument of the verb.
Das Kind ist sehr gewachsen.
the child is very grown
'The child has grown a lot.'

The cases discussed above illustrate two different sources of verbal scales. The first option is that the scale is lexicalized by the verb as in (54) or (46). A second option is that the scale is retrieved from our conceptual knowledge associated with one of the attributes of the verb, for example, an implicit argument. There is also a third option: the scale can be introduced by a morphosyntactic device like a resultative predicate. For verbs that do not lexically encode a change of state, the resultative construction introduces a change of state predication. The construction in (55) denotes a change 
which leads to the result that the child is hoarse at the end of the event. Following the analysis in chapter 3, the construction introduces a scale measuring the change of the subject referent.

\section{Das Kind schrie sich heiser. the child cried REFL hoarse 'The child cried itself hoarse.'}

Only verbs that lexicalize a scale express a scalar predication (in every context); the other two types of scales require a special (morphosyntactic) context. The diversity regarding verbal gradation scales makes it impossible to postulate one general rule of semantic composition for verbal degree gradation. Löbner (2012b) claims that verbal degree gradation is a subcompositional construction. A syntactic construction is subcompositional if there is no uniform rule of semantic composition for this construction (Löbner, 2012b, 224). Löbner's general claim is that there is not a single rule of semantic composition for the construction 'sehr + verb' but different rules depending on the semantic class of the graded verb.

In the last section, a single compositional rule for the construction 'very/sehr + adjective' has been presented. Hence, adjectival degree gradation is not subcompositional and therefore subcompositionality is the crucial factor distinguishing verbal degree gradation from adjectival degree gradation. The case studies on degree gradation of three different classes of gradable verbs, in the chapters 6 to 8, will illustrate the different compositional patterns in more detail. After presenting the case studies, I will come back to the notion of 'subcompositionality' in chapter 9 .

Due to subcompositionality, I will not provide a compositional analysis of verbal degree gradation in the following chapter but only indicate the outcome of the subcompositional process. Therefore, I will also not discuss the standard of comparison in verbal degree gradation but restrict myself to the interpretation of verbal degree gradation and the question how the gradation scales are related to the lexical meaning of the graded verbs.

Subcompositionality of verbal degree gradation is deeply connected with the fact that many gradable verbs are lexically non-scalar. The scale is activated from the conceptual knowledge associated with the verb and there is a different functional relation between the scale and the eventuality denoted by the verb from different classes of verbs. Furthermore, the fact that 
many gradable verbs do not lexically encode a scale makes a big difference between verbal degree gradation and gradation of adjectives. As discussed in 5.1, gradable adjectives are lexically scalar and based on Kennedy (1999b) and Kennedy \& McNally (2005a) it is reasonable to assume that they have a degree argument. Due to this big difference regarding lexical scalarity, the analysis of adjectival degree gradation cannot be adopted for the case of verbal degree gradation.

\subsection{Conclusion}

Starting from a discussion of adjectival degree gradation, the current chapter revealed two essential differences between adjectical and verbal gradation. First, verb gradation is subcompositional, whereas adjectival gradation is not. Second, the scale is the semantic core of gradable adjectives but it is not a meaning component of most gradable verbs. Rather, the scale has to be retrieved from the conceptual knowledge associated with the verb. Most gradable verbs do not express a scalar predication and so there is no need to postulate a degree argument for these verbs. But it is a different question for lexically scalar verbs such as change of state verbs and scalar stative dimensional verbs. I will turn to a discussion of change of state verbs as a prototypical example of scalar verbs in the next chapter. 